\title{
THE EULER-MAYER CORRESPONDENCE
}

(1751-1755) 


\section{The Euler-Mayer Correspondence \\ (1751-1755)}

A NEW PERSPEGTIVE ON EIGHTEENTH-GENTURY

ADVANCES IN THE LUNAR THEORY

by

ERIC G. FORBES

University of Edinburgh

Macmillan Education 
(C) E. G. Forbes, 1971

Softcover reprint of the hardcover 1st edition 1971

All rights reserved. No part of this publication may be reproduced or transmitted in any form or by any means without permission

First published 1971

Published by

THE MAGMILLAN PRESS LTD

London and Basingstoke

Associated Companies in New Tork, Toronto, Melbourne, Dublin, Johannesburg and Madras

ISBN 978-1-349-01252-7 ISBN 978-1-349-01250-3 (eBook)

DOI 10.1007/978-1-349-01250-3

TO MY GRANDMOTHER 


\section{CONTENTS}

$\begin{array}{lr}\text { Preface } & \begin{array}{r}\text { Page } \\ \text { vii }\end{array} \\ \text { Introduction } & 1 \\ \text { References } & 23 \\ \text { Correspondence } & 31 \\ \text { Notes } & 99 \\ \text { Index } & 116\end{array}$




\section{PREFAGE}

The major justification for publishing an English translation of the thirtyone letters which constitute the known correspondence between the Swissborn mathematician Leonhard Euler (1707-83) and the German astronomer Tobias Mayer (1723-62) rests in the contribution of its central theme-the theory of the Moon's motion - to the acceptance of the Newtonian philosophy during the eighteenth century. Not only was the lunar theory then being regarded as a test case for the validity of interpreting the physical world in terms of the geometrical axioms of Newtonian mechanics, but it was at the same time providing a stimulus to the development of mathematics by revealing the need for a greater degree of generality and rigour in the new analytical methods which Euler himself, Alexis Clairaut (1713-65) and Jean d'Alembert (1717-83) were among the first to adopt. The independent researches of these three men mark the beginning of a new and very fertile phase in the history of physical astronomy, which culminated with the publication of the first volume of Pierre Simon de Laplace's Mécanique Céleste (5 vols., Paris, 1799-1825). Newton's axioms of motion and his hypothesis of an inverse-square law of gravitational attraction provided a sufficient basis for the brilliant achievements of celestial mechanics embodied in this monumental work; thus astronomy became even more intimately linked with geometry, and the long-term stability of the solar system was assured without the need to introduce the transcendental hypothesis of a Divine Being - so necessary a feature of Newton's own providential explanation of the structure of the solar system.

Mayer's own rôle in this development has been summarised by the nineteenth-century historian of astronomy Robert Grant, on p. 208 of his History of Physical Astronomy (London, 1852), as follows:

Mayer has earned for himself an imperishable reputation by his lunar tables. Some astronomers may have achieved results of greater brilliancy, but few have been privileged to contribute so directly to the well-being of their fellow-men.

Even independently of the improvement which he effected in this instance, Mayer possesses claims to be ranked with the greatest astronomers of ancient or modern times; but as in the case of either of his illustrious contemporaries, Bradley or Lacaille, his labours are not of a nature to be generally appreciated, and therefore his reputation is less widely diffused than that of many an individual whose contributions to science, though more showy, are infinitely less substantial.

Although it is undoubtedly true that the complexity of Mayer's researches was a reason for the subsequent lack of diffusion of his results, it is equally 
significant that his pioneering efforts to improve the position of geodetic, navigational and astronomical instruments were quickly superseded in this period of rapid growth in the physical sciences. Moreover, a considerable portion of his work has never been published, and that which has been is either in Latin or in German; thus it has hitherto remained inaccessible to many potentially-interested students of astronomy in English-speaking countries.

In view of the fact that a great deal of insight into the nature of Mayer's labours can be gained from a study of this correspondence with Euler, and that Mayer's lunar tables (not Euler's) were directly responsible for the significant improvements that occurred in navigational practice during the latter half of the eighteenth century, it was decided to centre the Introduction upon the former rather than the latter. Additional factors influencing this decision were that: (i) Mayer is in any case the lesser known of the two correspondents; (ii) he wrote twenty of the thirty-one letters comprising this correspondence; and (iii) his initial researches in lunar theory were entirely dependent upon Euler's mechanical treatises, whereas the only clear evidence of a reciprocal influence is the latter's renewal of earlier investigations into the theory of astronomical refraction.

According to Sigmund Günther, who wrote the article on Tobias Mayer in the Allgemeine deutsche Biographie, xxi (1885), 109-16, the historian requires to take account of the latter's contributions to three distinct disciplines: mathematics, physics and astronomy. Such a classification of Mayer's writings tends, however, to suggest some kind of methodological distinction in the character of his treatises which simply does not exist. A more meaningful approach would be the straightforward chronological one, based upon the following four periods of Mayer's life: his youth in Esslingen (up to 1744); Augsburg (1744-46); Nuremberg (1746-51); and Göttingen (175162). Thanks to Paul Eberhardt, a former director of the Esslingen archives, the first period is as well documented as it can be; but a thorough search of the Augsburg and Nuremberg archives has failed to reveal any primary sources of information about Mayer's social circumstances during the years which he is known to have spent in these towns. However, the comparative scarcity of biographical material does not preclude the possibility of our being able to construct a consistent (if not accurate) interpretation of the motivation for his work and the nature of his scientific achievements from the internal evidence of his own writings.

This study has been made in the light not only of his correspondence with Euler, but of all the known documentary evidence by, or about, him-including a large quantity of his still unpublished treatises, lecture notes and correspondence which was allowed to lie practically neglected in the Göttingen University Observatory for over two hundred years. They were wisely transferred in the summer of 1965 to the local university library where 
the author has been able to acquire easy access to them. Although there are several aspects of Mayer's work which one might consider, the features which will be stressed here are that:

(a) the primary motivation for Mayer's astronomical researches was his devotion to the aim of improving the state of cartography by providing accurate determinations of terrestrial latitudes and longitudes; and that

(b) his success in constructing lunar tables which were at least five times as accurate as those of his famous contemporaries Clairaut, Euler and d'Alembert lay directly in his own personal skill in improving his observational technique-not in the greater profundity of his lunar theory nor in the superiority of the astronomical instruments at his disposal.

Mayer's researches, although they at first give the impression of being rather diversified in content, are characterised by a unity of purpose which makes it possible to judge the extent of Euler's influence upon them. To illustrate that influence, and to reveal the nature of Mayer's individual contributions to the development of the lunar theory, are the two prime aims of this book.

The translation of the correspondence itself has been made from the published copies of the German originals in the Russian periodical Историкоастрономические исследования, v (1959), 271-444 and x (1969), 285-310. References to the letters are indicated by square brackets; however, the numbering convention employed here is not the same as that used by $\mathrm{Dr}$ Y. K. Kopelevich in the earlier of the above-mentioned articles since it has had to be modified to take account of the subsequent discovery (by the author) of the four letters from Euler to Mayer printed in the later article. The bibliographical notes in Russian supplied by Dr Kopelevich herself, which Prof. A. J. Meadows, Department of Astronomy, University of Leicester, kindly translated for my benefit, have proved to be quite helpful, although their content has been checked independently wherever possible.

One of the best introductory surveys of developments in the lunar theory prior to the time of Newton is Hugh Godfray, An Elementary Treatise on the Lunar Theory (Cambridge, 1853). The historical sources on which a thorough and more comprehensive study of the lunar theory and its many associated aspects of astronomy would require to be based, are contained in J. C. Houzeau and A. Lancaster, General Bibliography of Astronomy to the Year 1880 , edited by D. W. Dewhirst (2 vols., London, 1964). A mine of untapped manuscript material on the various astronomical methods for finding longitude at sea is presently preserved at the Royal Greenwich Observatory, Herstmonceux Castle, Hailsham, Sussex, England, and is now available on microfilm; for details, see the author's "Index of the Board of Longitude 
Papers at the Royal Greenwich Observatory", fournal for the History of Astronomy, 1 (1970), 169-79.

It is the author's earnest hope that this booklet will encourage other historians of astronomy to explore this somewhat neglected field and thereby supply "grist to the mill" of historians of ideas who are inclined to oversimplify the eighteenth-century cultural scene by attributing too much to the direct influence of Newtonian science. As far as the question of motivation is concerned, the present study clearly reveals that Mayer's environmental circumstances, natural inclinations and urge to put German cartography on the map (as it were), had a more determinative influence upon the pattern of his astronomical researches than some innate conviction that the pathway to progress could be attained only through the application of Newtonian mechanics to the problems of the natural world.

ERIG G. Forbes

History Department,

University of Edinburgh,

Scotland

18 September 1969 